\title{
Organizational reshuffling to facilitate coordinated decisions in complex projects
}

Concurrent Engineering: Research and Applications

I-I |

(C) The Author(s) 2018

Reprints and permissions:

sagepub.co.uk/journalsPermissions.nav DOI: $10.1177 / 1063293 \times 18756718$

journals.sagepub.com/home/cer

\author{
Julien Ventroux, Franck Marle and Ludovic-Alexandre Vidal
}

\begin{abstract}
Oil and gas development projects are characterized by numerous contractual agreements. This forms a complex organization, with the challenge to coordinate diverse and interrelated stakeholders at different moments in the project. A critical issue is the communication and coordination between actors on cross-boundaries decisions. This is notably due to the classical definition of organizational boundaries, with several physical packages and, of course, several contractors. The approach consists in, first, modeling interdependencies between project elements such as product components, activities, and organizational entities. Second, some complex phenomena such as propagation chains and loops are identified, in order to anticipate potential undesired consequences if those are not properly managed. Third, an organizational reshuffling is computed, based on the double objective of incorporating at best within clusters the critical interactions and the critical complex phenomena. Results show an improvement on both objectives compared to current organization, meaning that communication and coordination about some crucial cross-boundaries decisions are expected to be facilitated within and between clusters. An industrial application in the oil and gas sector is introduced in order to highlight possible benefits and implementation strategies for such an approach.
\end{abstract}

\section{Keywords}

complex project management, project organization, coordination, clustering, propagation chains, loops, risk management

\section{Introduction}

Oil and gas platform is a complex product, with multiple interdependent packages, themselves broken into thousands of components down. The lifecycle of such installations starts with preliminary appraisal and conceptual studies, to validate the feasibility and opportunity of the development. Then, pre-project and development project are run in order to design and build the installation. In oil and gas context, there are several key milestones. One important milestone is related to the award process, which consists in signing contracts with external companies. As in many industries, oil and gas companies outsource or subcontract many activities, for different reasons related to cost, competence, or risk transfer. For oil and gas projects, each contract may represent up to several billions of dollars, and contracts globally represent approximately $80 \%-90 \%$ in value of the whole project. Multiple contracts are given to tens of contractors, who can be worldwide or locally established, mature or new on the market. Work is performed on a concurrent engineering basis, meaning that multiple processes are run in parallel, both for designing and building the installation.

This implies a complex organization, which requires the coordination and cooperation of employees from different organizations. This implies not only multiple risks of different natures, including over costs and delays, but also injuries and accidents (Milch and Laumann, 2016; Whitty and Maylor, 2009). Operating companies form coordination groups using classical parameters, such as organizational breakdown structure, product breakdown structure, lifecycle phases, and geographical areas.

Independently of the actual project complexity, which combines tightly coupled technical and

Laboratoire Genie Industriel, CentraleSupélec, Université Paris-Saclay, Chatenay-Malabry, France

Corresponding author:

Franck Marle, Laboratoire Genie Industriel, CentraleSupélec, Université Paris-Saclay, Grande voie des vignes, Chatenay-Malabry 92290, France. Email: franck.marle@ecp.fr 
organizational aspects (Bosch-Rekveldt et al., 2011), what is important is how this complexity is perceived and managed by human actors. It depends on the way actors are organized and communicate and make coordinated decisions. Oil and gas complex projects are characterized by the involvement of numerous contractors, subcontractors, and suppliers, linked with the company by contractual relationships. The latter may influence the capacity to cooperate and work under a concurrent engineering context.

A poor management of the relationships between the numerous actors may result in organizational issues, with possible negative consequences on the performance of the project. As mentioned by Yassine and Braha (2003),

the Iteration, Overlapping, and Decomposition and Integration problems address nontemporal ("structural" or "static") issues of product development such as team and product architecture formation, while the Convergence problem is concerned with temporal ("dynamic") aspects such as understanding the complex behavior of product development tasks over time.

Concurrent engineering is based on three basic elements (Koufteros et al., 2001): (1) concurrent workflow, (2) early involvement of all participants, and (3) teamwork. One of the concurrent engineering aims is to provide timely information to project participants (Addo-Tenkorang, 2011). Therefore, this work aims at improving the ability to share and communicate useful information on a timely basis between project members.

This article aims thus at proposing a complementary organizational structure taking into account interactions between stakeholders from different entities. This helps anticipating and mitigating risks related to poor communication and coordination while making key decisions, which is a recently highlighted emergent topic (Pitsis et al., 2014; Svejvig and Andersen, 2014). This is done using a mathematical approach called clustering. It is based on the modeling of strength of interactions between actors, including more specifically some phenomena associated with complex structures such as loops (or cycles) and propagation chains.

The remainder of this article is as follows: section "Related work" introduces literature about complex project organization and classical issues associated with this complexity. Section "Proposed approach" describes the research approach, based on the design research methodology approach applied post-mortem to a real past project. Section "Introduction of the case study" introduces the industrial application project. Section "Stage 1: modeling and analyzing project elements and their interactions" introduces the modeling approach which enables specific phenomena such as loops and chains to be detected. Section "Clustering approach to reshuffle project organization" describes the solving approach using clustering techniques, based on the previous model. Both sections are illustrated using the industrial example. Section "Discussion and managerial implications" presents a discussion on managerial implications of this work. Finally, section "Conclusion" draws some conclusions and perspectives for further work.

\section{Related work}

This section introduces classical approaches for modeling project complexity and detecting complex phenomena such as propagation chains and loops (cycles). Thus, organizational issues associated with the management of such complex phenomena are presented, followed by the introduction of clustering as a way to align the organization to these complex phenomena.

\section{Approaches for modeling project complexity}

The design structure matrix or dependency structure modeling (DSM) approach has been created by Steward (1981). It is a matrix-based description model of interactions between elements. It has the main advantage to mix four types of relationships between elements (Browning, 2001): dependent (e.g. sequential link between project activities (PAs)), interdependent (coupled), independent, and contingent (with some conditions).

Multiple works have been done on managing interdependencies within projects, for product-, process-, and organization-related analyses. The complexity of the result, here an oil and gas installation, determines the complexity of the numerous decisions to make and the numerous actions to undertake to design, build, and install such an installation. Organization modeling is useful since it assists the communication and coordination between actors, either internal or external to the company (Sosa et al., 2004). Finally, some works combine three dimensions using the multi-domain matrix (MDM) approach (Danilovic and Browning, 2007; Lindemann et al., 2009; Marle and Vidal, 2016).

\section{Detecting complex phenomena such as propagation chains and loops (cycles)}

The behavior of a complex project is characterized by linear and nonlinear phenomena, feedback loops, and emergent and chaotic behavior. In total, two specific phenomena are considered here, (1) propagation chains and (2) loops or cycles, which are a particular case 
where the chain is closed, since the final node is also the initial one. About propagation chains, Weick and Sutcliffe (2001) recommend to "pay close attention to weak signals of failure that may be symptoms of larger problems within the system." Indeed, risks with low individual criticality may be at the origin of chains with far higher final stakes (Fang and Marle, 2013). These nonlinear, amplifying phenomena are to be detected and managed in order to avoid transformation of initial low-level risk into high-level disruption, implying a change in the project behavior.

A feedback loop is defined as "a mechanism allowing to bring back as inputs of the system information which are directly dependent on output of the system" (Donnadieu et al., 2003).In total, three types of loops are classically introduced. (1) Positive or amplifying loops, with an evolution toward amplification of the initial phenomenon. Positive loops may evolve to chaotic states. (2) Negative or retroactive loops, with an evolution toward reduction in the initial phenomenon. Negative loops may evolve to stability state. (3) Agoantagonist loops, which can have one behavior or the other, with the difficulty or even the impossibility to predict polarity changes. Cyclicality is defined in product design context by Sosa et al. (2013) as follows: "how dependent a component is on itself via other product components." Component cycles inhibit the proper decomposition of design problems. It requires, therefore, concurrent or iterative problem solving, which results in cognitive and organizational challenges (Mihm et al., 2003).

The justification of focusing on specific complexityrelated phenomena has been analyzed notably by Sosa et al. (2013), who confirmed our proposal to encapsulate chains and cycles in organizational clusters. Loch and co-authors have shown the influence of local decisions on global performance landscape of development projects when these local elements are interdependent. Moreover, they have proposed classes of managerial actions, such as "limiting the effective system size of fully interdependent components, modularity, and cooperation among designers"(Loch et al., 2003).

\section{Organizational issues associated with the management of such complex phenomena}

Complex industrial projects, such as oil and gas development projects, generally have a dedicated organization. Even if external stakeholders (contractors, host country, partners, etc.) are crucial for making some decisions and carrying out the execution of some actions, it is noticed that they are not always enough integrated in project organization (Hill, 2013). Several authors (Cedergren, 2013; Milch and Laumann, 2016;
Nenonen and Vasara, 2013) precise that "if each organization stays in its own competence area, then holistic and integrated vision will be hard to have." Many problems and dysfunctions will thus occur, such as bad communication, bad coordination, and more broadly lack of trust.

A bad communication involves poor information circulation (Albrechtsen and Hovden, 2014; Nenonen and Vasara, 2013) and poor coordination while making collective decisions. This may be due to the mistrust or difficulty to develop trust between different actors, even within the same organization (Kochan et al., 1994).

Coordination dysfunctions may occur while making decisions, either by poor integration of multiple and contradictory information or by poor anticipation of indirect consequences of the decision (Love et al., 2013; Parrod et al., 2007; Turner and Simister, 2001).

Similarly, as in the organizational structure modeling and analysis (OMA) tool (Haque et al., 2000), we aim at providing a methodology and a computer-based analysis tool. This enables managers to continuously improve in a structured manner the project organization, as underlined by Pawar et al. (2002).

\section{Clustering as a way to align the organization to the detected complex phenomena}

Significant effort has been spent on developing new organizational paradigms "characterized by flatter hierarchies, decentralized decision-making, greater capacity for tolerance of ambiguity, permeable internal and external boundaries, and empowerment of employees, capacity renewal, self-organizing units, and selfintegrating co-ordination mechanisms" (Campagnolo and Camuffo, 2010). A way to reshuffle project organization is proposed in this work to increase interorganizational coordination and decrease potential risks associated with project complexity. Interactionbased clustering aims at proposing groups of elements, maximizing interaction rate within-clusters boundaries, independently of the individual characteristics of these elements. A lot of approaches exist for solving the clustering problem in numerous fields, including engineering and project management (Borjesson and HolttaOtto, 2014; Eppinger and Browning, 2012; Marle and Vidal, 2013; Sosa and Marle, 2013; Ventroux, 2016). They are generally based on one objective function formulation and several constraints, which aim at reflecting managerial intention in the desired organizational structure.

The aim in this work is thus to combine two aspects of complexity (Maylor et al., 2013): the structural complexity (referring to the number and types of elements and their relationships) and the dynamic complexity 
(referring to the potential behavior of the project). Classical clustering is more oriented on structural complexity, the static description of relationships between elements (number and strength). This is already a key building block to predict the behavior of the system (Oehmen et al., 2015). The introduction of specific phenomena related to the dynamic behavior, such as propagation chains or loops, is then an originality which brings a complementary objective to the clustering. The following section describes the research approach.

\section{Proposed approach}

Our research is based on the design research methodology approach (Blessing and Chakrabarti, 2009). Key steps are as follows:

Understand. The aim is to diagnose existing situation and formulate the problem. This has been explained in the two first sections of this article. Since the project complexity is not entirely tackled by project organization, there is a risk of bad communication and coordination between project actors.

Develop. The aim is to propose, by creating new practices or improving current ones, an approach that will bring elements of solutions to the previously described problem. A two-stage process is proposed in this work, which is an original combination of existing practices. The two stages will be, respectively, developed in sections "Introduction of the case study" and "Stage 1: modeling and analyzing project elements and their interactions":

- Stage 1: modeling and analyzing. This consists of the following steps:

- Modeling the elements (here, internal and external project actors) and interactions between these elements;

- Highlighting specific propagation chains and loops that have to be managed.

- Stage 2: clustering incorporating identified complex phenomena. This includes the following steps:

- Considering interactions between actors to form clusters;

- Incorporating within-clusters boundaries highlighted chains and loops, to mitigate associated risks.

Evaluate. The aim is to apply the proposed process to one or more cases. This is done in this work through a test on a past project. This example is illustrated along sections "Stage 1: modeling and analyzing project elements and their interactions" and "Clustering approach to reshuffle project organization" and discussed in section "Discussion and managerial implications."

Communicate. This is done through publishing and writing operational documents up. Several deliverables are outputs of this research, including research articles and communications, but also operational guidelines and tool for application on future projects.

\section{Introduction of the case study}

The approach has been applied post-mortem to a big offshore project, called here O\&G project. Data have been anonymized. The exploration area comprises four offshore reservoirs situated approximately $40 \mathrm{~km}$ from the coast of a western African country, $200 \mathrm{~km}$ from the onshore base, and between 600 and $1200 \mathrm{~m}$ water depth. Project delivery date was 44 months, for a production level of approximately 200,000 barrels of oil per day, and a several billion dollars budget. The Floating Production Storage and Offloading (FPSO) installation was the world's largest, with a complex subsea network, over a $600-\mathrm{km}^{2}$ area. An innovation has been introduced, allowing separating the gas on the seabed and pumping the liquids up to the FPSO. This innovative technology was vital in overcoming the project main challenge: producing the heavy, viscous oil from the Miocene reservoirs, which accounts for two-thirds of the reserves. A large number of new technologies have been proven and qualified through this project and are now available to the oil industry worldwide. Our study will focus on the modeling, analysis, and treatment of the interactions between the key actors, internal and external, assigned to this project: project team, headquarters, contractors, subcontractors, partners, host countries, and so on. The novelty of our approach is twofold. First, we use the vulnerability concept to quantify the interactions between actors. Second, we take into account the dynamics of these interactions by analyzing propagation phenomena (linear chain, feedback loops, multiple effects, etc.).

The two following sections describe the implementation of the two-stage process on this case study.

\section{Stage I: modeling and analyzing project elements and their interactions}

Project elements, related to product, process, and organizational dimensions, and their interactions have to be modeled. Then, potential chains and loops within complex networks have to be identified and considered or not as potentially dangerous. 


\section{Modeling elements and their interactions}

Interactions between identified elements are modeled through a matrix-based approach, based on the $D S M$ approach introduced in section "Related work," consisting of three matrices.

The first one models the key product deliverables (PD matrix), classically represented as a product breakdown structure, and their interactions. Those are classically described in product development literature through spatial, energy, information, and materialbased interactions (Eppinger and Browning, 2012).

In the O\&G project, PDs were associated with key components of the installation and associated equipment, such as FPSO; Subsea Separation and Production System (SSPS); Subsea Umbilical, Risers, and Flowlines (SURF); and Offloading System (OLS).

The second matrix models the main PAs, defined by the intersection of PDs and phases. Their interactions are mainly based on sequential link, which can also be from a downstream activity to an upstream activity (it models an iteration or rework). It is always a question in system analysis to choose a level of analysis, knowing that a system can always be broken down into subsystems (Austin, 2002). We chose to stay at an intermediary level, which is at the intersection of one product component and one project phase. The reason is twofold: (1) to have a balance between quality and quantity of information and (2) to be aligned with the level where such projects are managed. This is the contract level, corresponding to one or several PAs.

In the O\&G project, PAs were structured following the PDs $\times$ phases breakdown and assembled in contracts. Examples of phases are basic engineering, detailed engineering, procurement, construction, installation, and commissioning.

The third matrix models the organizational entities (actors, departments, and companies) contributing to these activities or to these deliverables (OE matrix). These contribution relationships are modeled through two matrices, respectively, deliverables-actors and activities-actors. The OE matrix is built from the two previous ones, by identifying interactions between actors through interactions between elements that actors manage or contribute to. For instance, if two activities are sequenced, then actors contributing to these activities are connected.

In the O\&G project, actors were structured at department level in the company (project department, affiliate, risk and interface management, etc.) and at organization level for external actors (host country authority, local communities, contractors, and subcontractors). The project organization is broken down into a classical chart, where the first level is the project manager and the second level consists of package managers.
Between these two levels are the support functions: risk manager, project control, quality assurance, and so on. Teams were mainly located in headquarters for project management and close to the contractors' installations or headquarters for the different packages. For instance, engineering offices may be in one place and manufacturing installations in another one. This means that the supervising teams of the operating company should be at different places at different phases of the project. Many reporting actions were carried out between the different actors: project management team and headquarters, project management team and affiliate headquarters, project management team and host country, and project management team and partners. It was mainly at the project level, and no specific structure was in place for internal coordination at lower levels, notably between packages, contracts, or phases.

These three DSMs are combined into a single MDM which links the three types of elements together. They are initially binary, when only existence of interactions is identified. Then, they are estimated to transform binary into numerical matrices.

Direct assessment of the interactions is proposed here, following a five-level Likert-type scale (Jamieson, 2004). It includes a zero value for the absence of interaction and four levels for describing the strength of the interaction (four being the strongest one). This permits to avoid the usual bias in assessment with scales with an odd number of levels. The risk is to select too often the middle level (Maigre, 2011). Estimates can be obtained through experience or expertise. Experience is rare for the moment, since closeout reports do not specifically aim at keeping information about interactions between elements. Expertise can be captured, either by asking directly to actors involved in each interaction (each interaction has to be assessed twice) or by asking to a few number of relevant members, such as project manager, risk manager, system manager, and interface manager (when this role exists). The interaction strength is dependent on several factors, such as (1) the number and criticality of exchanged deliverables, (2) the previous collaboration experience, and (3) the level of involvement of downstream actor in the upstream activity. Multiple points of view are required in order to avoid at best, even if not perfectly, bias and estimation errors which are inherent to human nature facing risks (Chapman, 1998).

In the O\&G project, the initial configuration was organized by packages and then contracts. The obtained MDM is quite big (112 elements), with a quite high density of $22 \%$ (non-null cells). This is due to the fact that some actors are acting as hubs, being connected to many other actors, and contributing or being involved in many activities. 


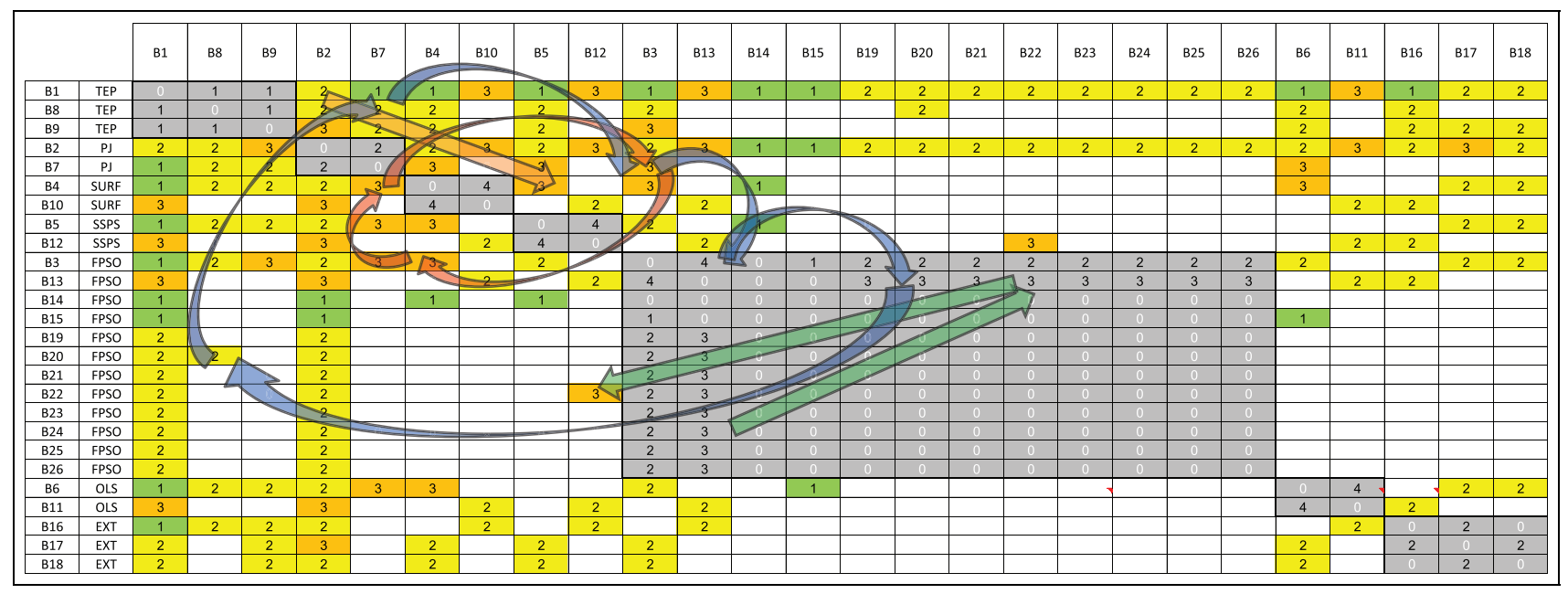

Figure I. Illustration of the potential dangerous phenomena identified within actor-actor OE matrix.

\section{Highlighting specific phenomena such as propagation chains and loops (cycles)}

Potential chains and loops within complex networks can be identified, thanks to the use of the powers of the binary interactions matrix (Ledet and Himmelblau, 1970). In this work, we use the binary version of the OE matrix, introduced in previous paragraph, which represents the existence (and not the strength) of interactions between organizational entities. Raising this matrix to the $n$th power permits to obtain a numerical matrix (with integer values), where a non-null element $(i, j)$ corresponds to the number of possible paths from element $j$ to $i$, the length of which being exactly $n$. Potential loops can then be identified, thanks to the diagonal elements of these matrices and potential chains can be identified using the non-diagonal elements. Identified chains and loops are then prioritized by decision makers, according to likelihood and severity. The conceptual originality of this work is to analyze the possibility to include these chains and loops within organizational groups for better communication and coordination about these potential dangers.

In the O\&G project, several chains and loops have been detected in OE, with a highlight on two chains and two loops with possible dangerous and/or amplifying effects (see Figure 1): chain 1 (B1-B2-B4-B5), chain 2 (B23-B13-B22-B12), loop 1 (B4-B3-B7), and loop 2 (B7-B3-B13-B20-B8). For illustration on loop 2, for instance, $\mathrm{B} 3$ is the manager of the FPSO package; $\mathrm{B} 13$ is the main contractor; and $\mathrm{B} 20, \mathrm{~B} 22$, and $\mathrm{B} 23$ are (among others) subcontractors (responsible for delivering a piece of the equipment or for doing a part of the process).

As shown in Figure 1, the complex phenomena involve actors who are in several organizational entities, located on different sites, possibly on different continents. This means that the management of such long chains or loops depends on the coordination of different and potentially conflicting interests. A total of $26.1 \%$ of the interactions are within current organizational boundaries (132 on a total of 512), and for the chains and loops, the incorporation indicators are, respectively, $0 \%$ for chain $1,66 \%$ for chain $2,0 \%$ for loop 1 , and $40 \%$ for loop 2 . This percentage is defined as the number of nodes and edges which are within a group (or cluster), divided by the total length of the chain. For a loop, of course, the length corresponds to a single iteration (otherwise, the length would be infinite).

The next step is thus to build clusters for coordinated management of interrelated elements, incorporating such phenomena.

\section{Clustering approach to reshuffle project organization}

The clustering approach is introduced in this section. First, the interaction-based clustering is introduced, based on previous work. Second, the originality of this work is introduced, which is to incorporate at best previously selected chains and loops in clusters.

\section{Interaction-based clustering}

Classical organizational structures (by phase, by product component, and by geographical site) do not permit to include the most critical interactions within their boundaries. Generally, most of the critical interactions and complex phenomena are out of organizational boundaries. The first objective is then to group 


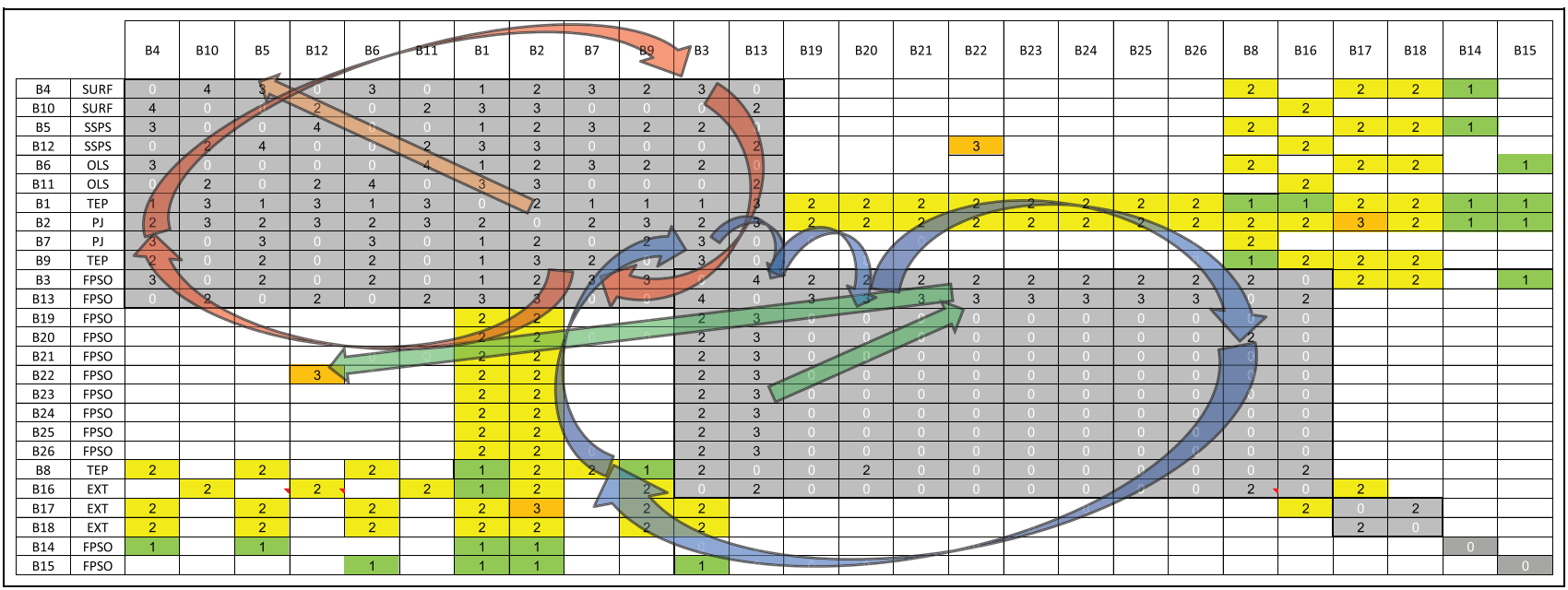

Figure 2. Clustering without incorporation of phenomena, with overlap.

Table I. Results for the different configurations.

\begin{tabular}{llll}
\hline Indicator & Initial configuration & $\begin{array}{c}\text { Intermediary (clustering } \\
\text { without incorporation) }\end{array}$ & $\begin{array}{c}\text { Complete (clustering } \\
\text { with incorporation) }\end{array}$ \\
\hline Percentage of interactions within clusters & 26.1 & 62.1 & 60.5 \\
Percentage of incorporation for chain I & 0 & 100 & 100 \\
Percentage of incorporation for chain 2 & 66 & 66 & 100 \\
Percentage of incorporation for loop 1 & 0 & 100 & 100 \\
Percentage of incorporation for loop 2 & 40 & 80 & 100 \\
\hline
\end{tabular}

elements according to the criticality level of their interactions. Several constraints are relevant here: first, the maximal number of actors allowed in clusters is crucial, both for calculation and practical implementation. Indeed, a 20-people cluster may be hard to implement and manage, especially to make coordinated decisions. Second, the disjunction of clusters, or more broadly the possibility for an actor to belong to one or more clusters, is also discussed. The implementation may be more difficult if actors are assigned to numerous clusters because of the effort and time required. It is even a challenge for visualization of results, if some actors are simultaneously included in more than two clusters. Despite visualization could be considered as a secondary objective, it has been recognized as an important factor of facilitation for understanding and even cooperation between actors who are involved in phenomena that may overwhelm their cognitive capacity (Killen and Kjaer, 2012). In this sense, Figure 2 is an easy-toread vision of proposed clusters, filled in gray, in order to highlight internal or external interactions and complex phenomena.

As shown in Table 1, 62.1\% of the interactions are within organizational boundaries. For the chains and loops, the incorporation indicators are, respectively,
$100 \%$ for chain $1,66 \%$ for chain $2,100 \%$ for loop 1 , and $80 \%$ for loop 2. As shown in Figure 2, specificity for the second loop is that it is partially incorporated into clusters 1 and 2. This means that the indicator of $80 \%$ in Table 1 comes from the addition of both percentages. It is to be noticed that albeit incorporating complex phenomena was not a target of the algorithm, clustering tends to group together these phenomena. This is notably due to the fact that they are highlighted as critical because of the strength of interactions they are composed of. The solution without overlap is far less performing (only $50 \%$ of the total of interactions).

This intermediary configuration is better than the initial one but does not permit to completely incorporate these potentially dangerous phenomena. The alternative strategy is thus to incorporate them within clusters, in addition to the basic objective of clustering by interactions. This is developed in the following paragraph.

\section{Incorporating specific chains and loops in clusters}

It is suggested to put actors involved in these phenomena together, in order to allow them to communicate and coordinate their decisions. The aim is to avoid or 


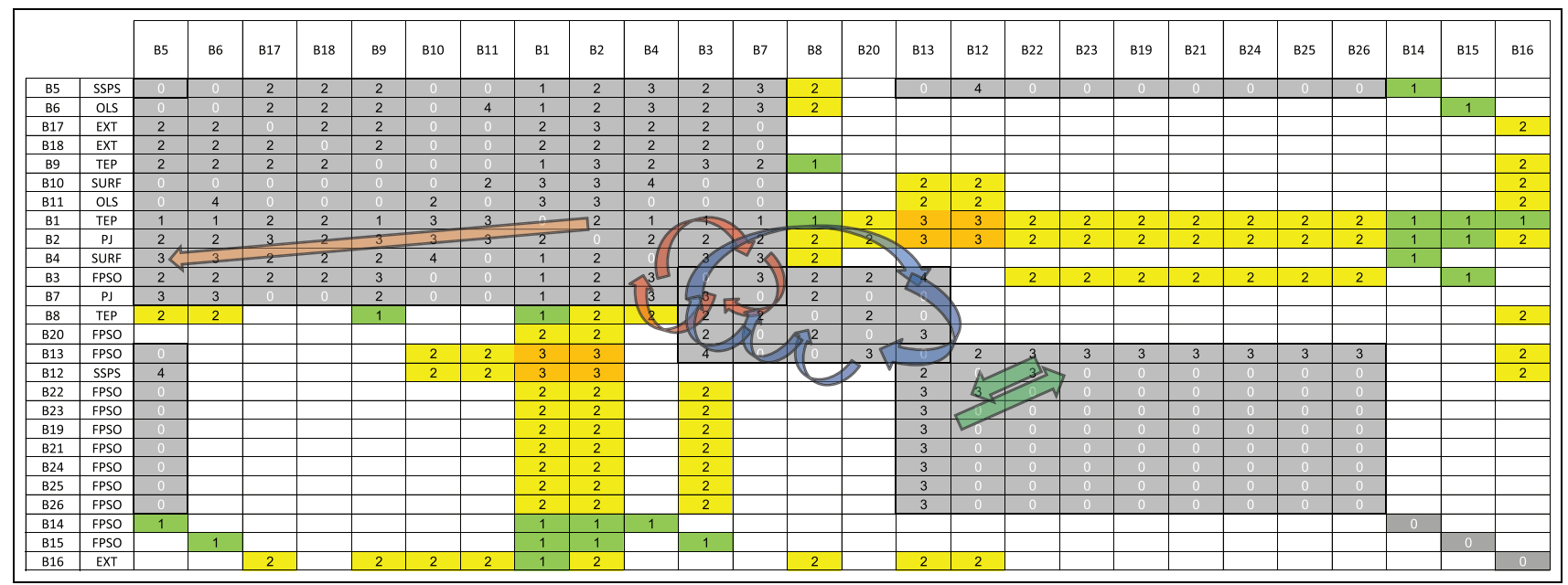

Figure 3. Illustration of the chosen clustered configuration.

at least to mitigate possible negative indirect consequences of the existence of these phenomena. In terms of algorithm description, the inclusion of a loop or a chain within a cluster may be realized through addition of several simultaneous inclusion constraints on the actors involved in the phenomenon. Once these actors are identified, they must be put together in the same cluster. The sensitivity of the algorithm is clearly related to the number, length, and possible interweaving of multiple phenomena. Indeed, some actors may be involved in two or more phenomena. It may, therefore, become unfeasible to satisfy the whole constraints because of cluster size constraint. Generally speaking, there is some contradiction between the trend to increase cluster size if loops and chains are included into them and the will to keep them under a reasonable size. There are two alternatives, with or without overlap permission. This supposes to stay reasonable on the number of simultaneous assignments and the number of elements with multiple assignments, for practical implementation.

In the O\&G project, several configurations are possible, with incorporation of complex phenomena or not, with or without overlap permission, and with different cluster sizes. Figure 3 shows the chosen one, with a maximal cluster size of 12 (corresponding to the biggest current group), overlap permission, and incorporation of complex phenomena. The overlap permission was mandatory, since some actors were involved in more than one phenomenon (B3 and B7 for loops 1 and 2, B13 for loop 2 and chain 2, and B4 for chain 1 and loop 1). Then, the second objective consisting in as much as possible critical interactions added the necessity to simultaneously put B5 in clusters $\mathrm{C} 1$ (for it belongs to chain 1) and $\mathrm{C} 3$ (for it is strongly related to B12).
As shown in Table 1, $60.5 \%$ of the interactions are within current organizational boundaries (310 on a total of 512). For the chains and loops, the incorporation indicators are $100 \%$ for the four phenomena (as shown in Figure 3).

The organizational benefits are illustrated hereunder, highlighting the difference between initial, intermediary, and clustered configurations (Table 1). Results are discussed in the next section, with implications on the management of such clusters.

\section{Discussion and managerial implications}

These initial results show that it is possible, under certain initial circumstances, to combine objectives of maximizing integration of interdependencies within clusters and integrating specific complexity-related phenomena. Both are compatible in terms of managerial implications, since they aim at better coordinating actions and decisions. However, they may be incompatible in terms of algorithm constraints, if there are too many phenomena or if they are strongly interweaved. In the latter case, if an element is involved into two phenomena, the possibility to put it into two clusters allows some flexibility. Finally, overlap permission and sufficient cluster size may compensate the negative influence of mandatory incorporation of specific phenomena within clusters. The additional effort required in case of overlap (since involved actors are assigned to two groups instead of one) is largely compensated by the gains, which are to incorporate undesired phenomena within clusters and simultaneously to have clusters with strong interactions.

Exploration of post-mortem projects is always difficult, since risk analyses may be biased by actual 
trajectory and knowledge of what happened. However, exploration of ongoing projects is not simple, since it is impossible to compare two projects, one with and one without tested approach. No placebo can be experimented in the case of several billion dollar projects, and no pair of projects is strictly identical. The decision has been made with managers of the oil and gas company involved in this study to implement the approach on a past project. One advantage was that more information was available, including information on risks and the way they had been managed. Decision makers confirmed after the study of the importance of such phenomena and the possible influence of the organization, since some propositions were in the "would do differently" section of the closeout report.

This article is a way to organize distributed coordination at operational levels (Ahern et al., 2013). We argue that a connected and concurrent organization is where communication and coordination about risks can be efficiently done, rather than analyzing a single 500-risk list. The desired consequence is to assist generating a more robust plan to guarantee at best a project due date and a final project cost. This is notably due to the fact that actors who work concurrently can know where the most dangerous risks are and can decide together mitigation strategies. For instance, buffers can be estimated to protect critical activities (Chun-Chao, 2008; Rand, 2000). Strategies for anticipating potential disruptions due to chains and loops can be undertaken (Kuster et al., 2009; Van Marrewijk et al., 2008; Weick and Sutcliffe, 2001; Zhu et al., 2004). Finally, anticipation of potential reactions of stakeholders can be done in order to facilitate a local coordination on global issues (Jepsen and Eskerod, 2009).

This is a kind of assistance to concurrent and distributed expertise, giving voice to the experts who are actively involved in currently not connected parts of the project organization. They are the ones who can at best notice early weak signals or mistakes. This is why it is worthy to put them together in order to (try to) solve collectively a problem they could not have dealt with individually. Specific relationships due to the presence of multiple contracts in waterfall do not by nature facilitate this kind of trust and collective work. It will not avoid all issues due to contractual relationships; however, it is one step in the good direction.

\section{Conclusion}

This article proposes an approach to build complementary project organizational structure. This reshuffling aims at facilitating the coordination between multiple and diverse actors involved in multiple and concurrent decision-making and action processes. The origin of the work is a need for detecting potential phenomena associated with the complexity of the project, anticipating their potential consequences and coordinating decisions about treatment strategies. This is all the more crucial in oil and gas projects since the organization is based on numerous and diverse actors linked with contractual relationships.

This is based on an original clustering approach, with the double objective of maximizing the number of interactions within clusters (corresponding to the structural complexity of the system) and incorporating specific complex phenomena such as chains and loops within these clusters (corresponding to the dynamical complexity of the system).

The originality and value of this work are then threefold. First, taking into account the existence and strength of relationships between project actors is an improvement compared to current industrial process. Second, focusing on specific complexity-related phenomena that could be potential dangers or possible opportunities is another improvement, since nothing was formalized in current project organization. Third, the organizational reshuffling through clustering enables to consider these two parameters. This is done by grouping actors for two reasons: (1) they are strongly connected to other actors and (2) they are involved in complex phenomena such as chains or loops.

Even without clustering, the first two points are already improvements compared to current industrial processes of the O\&G company partner of this work. The third point brings additional knowledge to the management of complex projects by combining two relevant, albeit potentially conflicting, parameters, which are, respectively, the percentage of interactions (in terms of strength) and the percentage of chains/loops (in terms of number of nodes of these chains/loops in the same cluster) within organizational boundaries. Communication and, therefore, coordination about crucial decisions are expected to be easier to make, since they are formalized in the agendas of working groups meetings (corresponding to clusters).

This work is the opportunity for further promising perspectives. For instance, a sensitivity analysis of the capacity to combine multiple objectives depending on the structure of matrices could be performed. This is all the more important since an extension of industrial application to further phases in the oil and gas installation lifecycle is planned. This means that matrices will become bigger and possibly more complex, with higher density, or at least with different structures, with more loops, for instance, or on the opposite with parallel independent chains. 


\section{Declaration of conflicting interests}

The author(s) declared no potential conflicts of interest with respect to the research, authorship, and/or publication of this article.

\section{Funding}

The author(s) received no financial support for the research, authorship, and/or publication of this article.

\section{References}

Addo-Tenkorang R (2011) Concurrent Engineering (CE): a review literature report. In: Proceedings of the world congress on engineering and computer science (WCECS) 2011, San Francisco, CA, 19-21 October.

Ahern T, Leavy B and Byrne P (2013) Complex project management as complex problem solving: a distributed knowledge management perspective. International Journal of Project Management 32(8): 1371-1381.

Albrechtsen E and Hovden J (2014) Management of emerging accident risk in the building and construction industry. In: Paper presented at working on safety. Scotland, UK, 30 September-03 October 2014.

Austin S (2002) Modelling and managing project complexity. International Journal of Project Management 20(3): 191-198.

Blessing L and Chakrabarti A (2009) DRM, a Design Research Methodology. London: Springer.

Borjesson F and Holtta-Otto K (2014) A module generation algorithm for product architecture based on component interactions and strategic drivers. Research in Engineering 25: 31-51.

Bosch-Rekveldt M, Jongkind Y, Mooi H, et al. (2011) Grasping project complexity in large engineering projects: the TOE (Technical, Organizational and Environmental) framework. International Journal of Project Management 29(6): 728-739.

Browning T (2001) Applying the design structure matrix to system decomposition and integration problems: a review and new directions. IEEE Transactions on Engineering Management 48(3): 292-306.

Campagnolo D and Camuffo A (2010) The concept of modularity in management studies: a literature review. International Journal of Management Reviews 12(3): 259-283.

Cedergren A (2013) Implementing recommendations from accident investigations: a case study of inter-organizational challenges. Accident Analysis and Prevention 53: 133-141.

Chapman R (1998) The effectiveness of working group risk identification and assessment techniques. International Journal of Project Management 16(6): 333-343.

Chun-Chao CHU (2008) Buffer sizing and critical chain project management [J]. Computer Integrated Manufacturing Systems 5(14): 1029-1035.

Danilovic M and Browning T (2007) Managing complex product development projects with design structure matrices and domain mapping matrices. International Journal of Project Management 25: 300-314.
Donnadieu G, Durand D, Neel D, et al. (2003) L'Approche systémique: de quoi s'agit-il? Paris: AFSCET.

Eppinger S and Browning T (2012) Design Structure Matrix Methods and Applications. Cambridge, MA: MIT Press.

Fang C and Marle F (2013). Dealing with project complexity by matrix-based propagation modelling for project risk analysis. Journal of Engineering Design 24(4): 239-256.

Haque B, Pawar K and Barson R (2000) Analysing organisational issues in concurrent new product development. International Journal of Production Economics 67(2): $169-182$.

Hill G (2013) The Complete Project Management Office Handbook. Boca Raton, FL: CRC Press.

Jamieson S (2004) Likert scales: how to (ab)use them. Medical Education 38(12): 1217-1218.

Jepsen A and Eskerod P (2009) Stakeholder analysis in projects: challenges in using current guidelines in the real world. International Journal of Project Management 27(4): 335-343.

Killen C and Kjaer C (2012) Understanding project interdependencies: the role of visual representation, culture and process. International Journal of Project Management 30(5): 554-566.

Kochan T, Smith M, Wells J, et al. (1994) Human resource strategies and contingent workers: the case of safety and health in the petrochemical industry. Human Resource Management 33(1): 55-77.

Koufteros X, Vonderembse M and Doll W (2001) Concurrent engineering and its consequences. Journal of Operations Management 19(1): 97-115.

Kuster J, Jannach D and Friedrich G (2009) Extending the RCPSP for modeling and solving disruption management problems. Applied Intelligence 31(3): 234-253.

Ledet W \& Himmelblau D (1970) Decomposition Procedures for the Solving of Large Scale Systems. Advances in Chemical Engineering 8:185-254.

Lindemann U, Maurer M and Braun T (2009) Structural Complexity Management: An Approach for the Field of Product Design. Berlin: Springer.

Loch C, Mihm J and Huchzermeier A (2003) Concurrent engineering and design oscillations in complex engineering projects. Concurrent Engineering: Research and Applications 11(3): 187-199.

Love P, Park M and Han S (2013) System dynamics modeling in the project environment. Mathematical and Computer Modelling 9(57): 2029-2031.

Maigre A (2011) Optimisation du modèle de scoring des rapports d'audit interne pour les organizations d'envergure internationale. MSc Thesis, Louvain School of Management, Louvain-la-Neuve.

Marle F and Vidal LA (2013) Forming risk clusters in projects to improve coordination between risk owners. Journal of Management in Engineering 30(4): 06014001.

Marle F and Vidal LA (2016) Managing Complex, High-Risk Projects. London: Springer.

Maylor H, Turner N and Murray-Webster R (2013) How hard can it be? Actively managing complexity in 
technology projects. Research-Technology Management 56(4): 45-51.

Mihm J, Loch C and Huchzermeier A (2003) Problem-solving oscillations in complex engineering projects. Management Science 49(6): 733-750.

Milch V and Laumann K (2016) Inter-organizational complexity and organizational accident risk: a literature review. Safety Science 82: 9-17.

Nenonen S and Vasara J (2013) Safety management in multiemployer worksites in the manufacturing industry: opinions on co-operation and problems encountered. International Journal of Occupational Safety and Ergonomics 19(2): 167-183.

Oehmen J, Thuesen C, Parraguez P, et al. (2015) Complexity management for projects, programmes, and portfolios: an engineering systems perspective. White paper. Newtown Square, PA: Project Management Institute.

Parrod N, Thierry C, Fargier H, et al. (2007) Cooperative subcontracting relationship within a project supply chain: a simulation approach. Simulation Modelling Practice and Theory 15(2): 137-152.

Pawar K, Haque B and Weber F (2002) Computer based initiatives for implementing and sustaining concurrent engineering. Concurrent Engineering: Research and Applications 10(1): 75-93.

Pitsis T, Sankaran S, Gudergan S, et al. (2014) Governing projects under complexity: theory and practice in project management. International Journal of Project Management 32(8): 1285-1290.

Rand G (2000) Critical chain: the theory of constraints applied to project management. International Journal of Project Management 18(3): 173-177.

Sosa M, Eppinger S and Rowles C (2004) The misalignment of product architecture and organizational structure in complex product development. Management Science 50(12): 1674-1689.
Sosa ME and Marle F (2013) Assembling creative teams in new product development using creative team familiarity. Journal of Mechanical Design 135(8): 081009.

Sosa M, Mihm J and Browning T (2013) Linking cyclicality and product quality. Manufacturing \& Service Operations Management 15(3): 473-491.

Steward D (1981) The design structure system: a method for managing the design of complex systems. IEEE Transactions on Engineering Management 28(3): 71-74.

Svejvig P and Andersen P (2014) Rethinking project management: a structured literature review with a critical look at the brave new world. International Journal of Project Management 33(2): 278-290.

Turner J and Simister S (2001) Project contract management and a theory of organization. International Journal of Project Management 19(8): 457-464.

Van Marrewijk A, Clegg S, Pitsis T, et al. (2008) Managing public-private megaprojects: paradoxes, complexity, and project design. International Journal of Project Management 26(6): 591-600.

Ventroux J (2016) Aide à la maîtrise des risques liés à la contractualisation et l'exécution d'un projet complexe pétrolier. Doctoral dissertation, Université Paris-Saclay, ChatenayMalabry.

Weick K and Sutcliffe K (2001) Managing the Unexpected: Assuring High Performance in an Age of Complexity. San Francisco, CA: Wiley.

Whitty S and Maylor H (2009) And then came complex project management. International Journal of Project Management 27(3): 304-310.

Yassine A and Braha D (2003) Complex concurrent engineering and the design structure matrix method. Concurrent Engineering: Research and Applications 11(3): 165-176.

Zhu G, Bard J and Yu G (2004) Disruption management for resource-constrained project scheduling. Journal of the Operational Research Society 56(4): 365-381.

\section{Author biographies}

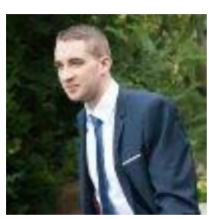

Julien Ventroux is an independent consultant since 2017. He formerly obtained his $\mathrm{PhD}$ from CentraleSupélec in Complex Project Management, working in collaboration with Total on how to manage risks linked with contracts in development projects.

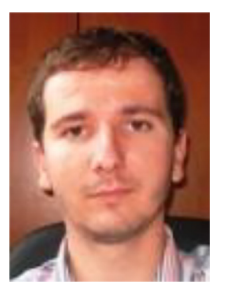

Franck Marle is full professor at CentraleSupélec, head of the Design Engineering research group in the Industrial Engineering research department. He is also director of the Chair with the oil \& gas company Total, entitled "Managing Procurement Risks in Complex Projects". He held numerous research projects on modeling and analysis of project complexity in order to help decision-making in complex and risky projects.

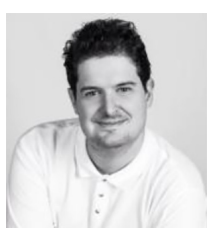

Ludovic-Alexandre Vidal is assistant professor at CentraleSupélec, specialized in complexity analysis and project risk management. He applies some results of his research in his other activity in the artistic field (event organization, musical show creation). 